\title{
To Identify the Role of Longitudinal Measurements of Foetal Aortic Isthmus Blood flow using Doppler Ultrasonography in the prediction of Perinatal Morbidity and Mortality
}

\author{
Renu Goindani ${ }^{1}$, Nirmal Kumar Mittal' ${ }^{2}$ Jagdish Kumar Gupta ${ }^{3}$, Aparna Gupta ${ }^{4}$ \\ ${ }^{1}$ Associate Professor, ${ }^{2}$ Assistant Professor, ${ }^{3}$ Senior Resident, ${ }^{4}$ Senior Resident, Department of Radio-Diagnosis, Amaltas \\ Institute of Medical Sciences, Dewas
}

Corresponding author: Dr. Nirmal Kumar Mittal, Assistant Professor, Department of Radio-Diagnosis, Amaltas Institute of Medical Sciences, Dewas

DOI: http://dx.doi.org/10.21276/ijcmsr.2019.4.1.25

How to cite this article: Renu Goindani, Nirmal Kumar Mittal, Jagdish Kumar Gupta, Aparna Gupta. To identify the role of longitudinal measurements of foetal aortic isthmus blood flow using doppler ultrasonography in the prediction of perinatal morbidity and mortality. International Journal of Contemporary Medicine Surgery and Radiology. 2019;4(1):A102-A104.

\section{A B S T R A C T}

Introduction: Arterial Doppler waveforms are related to both input pressure and downstream vascular resistance. Study aimed to identify the role of Longitudinal measurements of Foetal Aortic Isthmus blood flow using Doppler Ultrasonography in the prediction of Perinatal Morbidity and Mortality.

Material and methods: Present study was carried out in the Department of Radiology, Index medical College Hospital and Research Centre, Indore during the period of 18 months from Nov 2015 to April 2017. Patient's clinical history and examination findings were recorded prospectively in a proforma form. All sonographic results were recorded and evaluated prospectively.

Result: Sensitivity of IFI for perinatal outcome - 33.3\%, Specificity - 85\%,PPV - 50\%, NPV-75\% with non significant $\mathrm{p}$ value. In Umbilical Artery and these resulted in adverse perinatal outcome in the form of Respiratory distress Syndrome, Birth asphyxia, sepsis, IUD.

Conclusion: The occurrence of retrograde blood flow in the AoI is associated with adverse perinatal outcome. Growthrestricted preterm foetuses showed decreased absolute velocities in the AoI, very likely reflecting reduced systemic blood flow. Combination of AoI \& umbilical artery Doppler is the best indicator for prediction of IUGR. Aortic Isthmus changes occur 24-48 hrs before deterioration of flow in Ductus Venosus. Consequently, Doppler study may be used for the prediction of fetal outcome to reduce the maternal and perinatal morbidity and mortality.

Keywords: Foetal Aortic, Isthmus, Doppler, USG, Perinatal, Morbidity \& Mortality.

Study Designed: Observational Study.

\section{INTRODUCTION}

Fetal arterial Doppler evaluation has mainly utilized the umbilical artery, fetal aorta, \& middle cerebral artery. Doppler assessment of these \& other, fetal arteries provides information on regional blood flow \& perfusion of individual organs, as well as giving insights into the fetal circulatory state in health and disease. ${ }^{1}$

The Doppler indices measured at the fetal end, the free loop and the placental end of the umbilical cord are different with the impedance highest at the fetal end. The changes in the indices are likely to be seen at the fetal end first. Ideally the measurements should be made in the free cord.

Small-for-gestational age (SGA) fetuses with normal umbilical artery (UA) Doppler have been the focus of many clinical research studies with recent evidence suggesting that a substantial proportion may have true growth restriction as evidenced by poor perinatal outcomes. ${ }^{2}$ Intrauterine growth restriction (IUGR) is a progressive vascular disorder culminating in multivessel fetal hemodynamic abnormalities associated with stillbirth, perinatal morbidity, and cerebral palsy. ${ }^{3}$ Safe prolongation of pregnancy with timed delivery remains the mainstay of management. Due to a lack of robust data or consensus, it is unclear which method of assessment is the most useful to trigger the decision to deliver. Longitudinal data have suggested a predictable sequence of responses to placental dysfunction. ${ }^{4-5}$

Study was done to identify the role of Longitudinal measurements of Foetal Aortic Isthmus blood flow using Doppler Ultrasonography in the prediction of Perinatal Morbidity and Mortality.

\section{MATERIAL AND METHODS}

Present study was carried out in the Department of 
Radiology , Index medical College Hospital and Research Centre, Indore during the period of 18 months from Nov 2015 to April 2017.

Patient's clinical history and examination findings were recorded prospectively in a proforma form. All sonographic results were recorded and evaluated prospectively. The Isthmic Flow Index (IFI) was calculated using the following formula: $\mathrm{IFI}=(\mathrm{S}+\mathrm{D}) / \mathrm{S}^{6}$ where $\mathrm{S}$ and $\mathrm{D}$ are, respectively, the systolic and diastolic Doppler blood flow velocity integrals. If IFI was 1 , the flow was anterograde, and if IFI was $<1$, the flow was retrograde. In all cases, AI flow was taken. Fetal Gestational Age was calculated according to the maternal Last Menstrual Period and confirmed by first Trimester Ultrasound Crown-Rump Length. If the difference between Crown-Rump Length and Last Menstrual Period was more than seven days, the Crown-Rump Length calculation was accepted as the Gestational Age.

Estimated foetal weight was calculated using the Biparietal diameter, Abdominal Circumference and Femur length measurements as observed by Ultrasound. Estimated foetal weight $<10$ th percentile for Gestational Age was considered equivalent with IUGR, and this diagnosis was confirmed after birth. UA, Middle Cerebral Artery (MCA) and AI Doppler measurements was performed. All measurements were performed in the supine and left lateral tilt position, but not during fetal movement, fetal respiration or uterine contractions. The AI Doppler measurement was performed using the longitudinal Aortic Arch or three- vessel and trachea section with an insonation angle of $<30^{\circ}$. An MCA pulsatility index (PI) of $<5$ th percentile for Gestational Age was considered a brain sparing effect. If IFI was $<1$, the flow was considered retrograde (abnormal).

\section{Inclusion criteria}

1) Subjects between 28 to 37 weeks of gestation.

2) Subjects with high risk pregnancy (Pre-eclampsia, Anaemia, previous history of IUGR.)

3) Pregnancies with abnormal previous Doppler scan.

4) Follow-up patient in the institution during the study period.

\section{Exclusion criteria}

1) Subjects not giving consent to be a part of the study.

2) Pregnancies independent of risk factors.

3) Pregnancies with normal Doppler measurement.

\section{STATISTICAL ANALYSIS}

Data was depicted in the form of tables and charts. Chi square tests on various perinatal variables on SPSS 20.0. Microsoft Excel was used for data analysis.

\section{RESULT}

Maximum 50\% of case was seen in Respiratory Distress Syndrome, followed by Birth asphyxia, Acidosis, IUFD, Sepsis $10 \%$ case was seen each of them in Case Group, whereas in Control Group Maximum 77.1\% were Normal followed by $14.2 \%$ Respiratory Distress Syndrome \& 8.5 Birth asphyxia (table-1).

Maximum 50\% of case was seen in IUFD \& 50\% case were Normal in Case Group, whereas in Control

\begin{tabular}{|l|c|c|c|c|}
\hline \multirow{2}{*}{ Perinatal Outcome } & \multicolumn{4}{|c|}{ Aortic Isthmus Index } \\
\cline { 2 - 5 } & \multicolumn{2}{|c|}{ Cases(<1) } & \multicolumn{2}{c|}{ Control( > 1 ) } \\
\cline { 2 - 5 } & No & $\%$ & No & $\%$ \\
\hline Respiratory Distress Syndrome & 05 & $50 \%$ & 05 & $14.2 \%$ \\
\hline Birth asphyxia & 01 & $10 \%$ & 03 & $8.5 \%$ \\
\hline Acidosis & 01 & $10 \%$ & 00 & - \\
\hline IUFD & 01 & $10 \%$ & 00 & - \\
\hline Sepsis & 01 & $10 \%$ & 00 & - \\
\hline Normal & 01 & $10 \%$ & 27 & $77.1 \%$ \\
\hline
\end{tabular}

Table-1: Association of aortic isthmus index with perinatal outcome in IUGR $(\mathrm{N}=45)$

\begin{tabular}{|l|c|c|c|c|}
\hline \multirow{2}{*}{ Perinatal Outcome } & \multicolumn{4}{|c|}{ Aortic Isthmus Index } \\
\cline { 2 - 5 } & \multicolumn{2}{|c|}{ Cases (<1) } & \multicolumn{2}{c|}{ Control (> 1 ) } \\
\cline { 2 - 5 } & No & $\%$ & No & $\%$ \\
\hline Respiratory Distress Syndrome & 00 & - & 01 & $12.50 \%$ \\
\hline Birth asphyxia & 00 & - & 01 & $12.50 \%$ \\
\hline Acidosis & 00 & - & 00 & - \\
\hline IUFD & 01 & $50 \%$ & 00 & - \\
\hline Sepsis & 00 & - & 00 & - \\
\hline Normal & 01 & $50 \%$ & 06 & $75 \%$ \\
\hline
\end{tabular}

Table-2: Association of aortic isthmus index with perinatal outcome in previous IUGR $(n=10)$

\begin{tabular}{|l|c|c|c|}
\hline & IFI>1 & IFI <1 & Marginal row total \\
\hline Adverse outcome & 1 & 2 & 3 \\
\hline Normal outcome & 1 & 6 & 7 \\
\hline Marginal column total & 2 & 8 & 10 \\
\hline Chi square stats-0.476, P=.49015 ( Nonsignificant) \\
\hline Sensitivity- 33.3\%, Specificity - 85\%,PPV - 50\%, NPV-75\% \\
\hline Table-3: Statistical calculation of ifi and its perinatal outcome \\
in previous IUGR \\
\hline
\end{tabular}

\begin{tabular}{|l|c|c|c|c|}
\hline \multirow{2}{*}{ Perinatal Outcome } & \multicolumn{4}{|c|}{ Aortic Isthmus Index } \\
\cline { 2 - 5 } & \multicolumn{2}{|c|}{$(<\mathbf{1})$} & \multicolumn{2}{c|}{$(>\mathbf{1})$} \\
\cline { 2 - 5 } & No & $\%$ & No & $\%$ \\
\hline Respiratory Distress Syndrome & 00 & - & 00 & - \\
\hline Birth asphyxia & 01 & $50 \%$ & 00 & - \\
\hline Acidosis & 00 & - & 01 & $7.6 \%$ \\
\hline IUFD & 00 & - & 00 & - \\
\hline Sepsis & 00 & - & 00 & - \\
\hline Normal & 01 & $50 \%$ & 12 & $92.3 \%$ \\
\hline \multicolumn{4}{|c|}{ Table-4: Association of aortic isthmus index with perinatal } \\
outcome in anemia (N=15) \\
\hline
\end{tabular}

Group Maximum 75\% were Normal followed by $12.5 \%$ Respiratory Distress Syndrome \& 12.5\% Birth asphyxia (table-2).

Sensitivity of IFI for perinatal outcome - 33.3\%, Specificity - 85\%,PPV - 50\%, NPV-75\% with non significant $\mathrm{p}$ value as discussed in the above table (table-3).

In Umbilical Artery and these resulted in adverse perinatal outcome in the form of Respiratory distress Syndrome, Birth asphyxia, sepsis, IUD as shown in the table-4.

Figure- 1 and figure- 2 shows antegrade flow in aortic isthmus and retrograde flow in aortic isthmus respectively. 


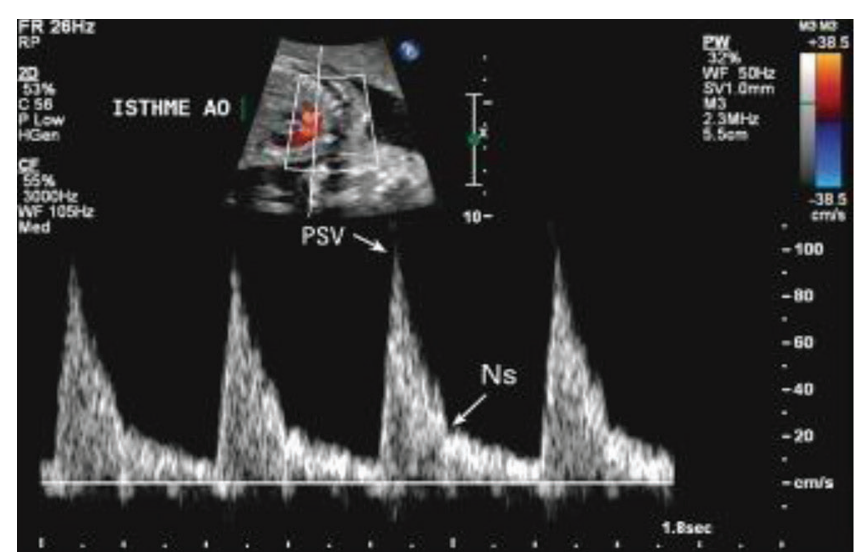

Figure-1: Showing Antegrade Flow in Aortic Isthmus

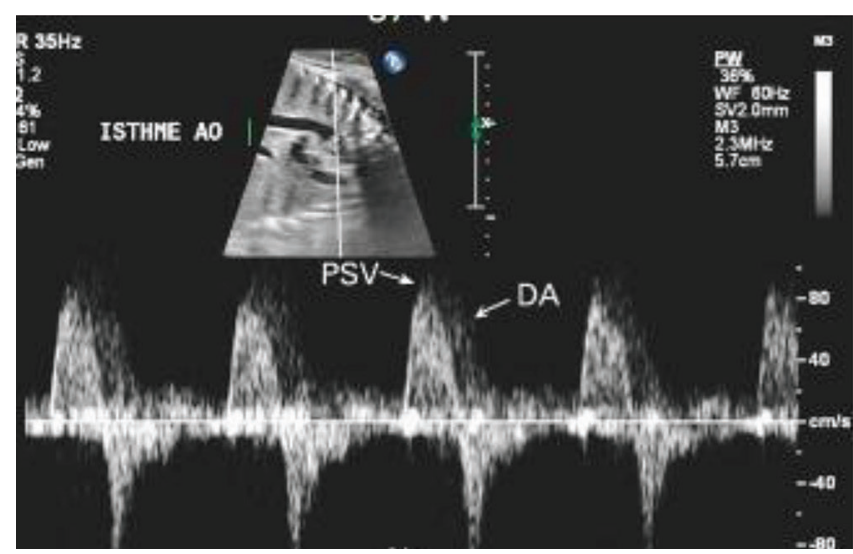

Figure-2: Showing Retrograde Flow in Aortic Isthmus

\section{DISCUSSION}

Fouron et al. $2001^{7}$ evaluated the association between an abnormal aortic isthmus blood flow index and postnatal neuro- developmental outcome in foetuses with placental circulatory insufficiency and he reported that neurological development in children two to five years of age who had FGR and abnormal UA blood flow was better for those who had anterograde AI blood flow rather than retrograde. The most important limitation of this study was the sample size. He found an inverse correlation between the isthmus blood flow index and postnatal neuro developmental outcome. An isthmus blood flow index cut-off value of 0.70 was associated with the highest overall positive and negative predictive values. The pulsatility index in the umbilical artery did not provide any significant contribution in the explanation of the outcome.

Ropacka-Lesiak et al $2011^{8}$ evaluated the relation between retrograde diastolic blood flow in the aortic isthmus and adverse perinatal outcome in fetuses with IUGR. Based on these parameters: umbilical cord blood $\mathrm{pH}<7.2 ; 5$-minute Apgar score < 7; respiratory distress syndrome, intraventricular hemorrhage (11/IV grade); necrotizing enterocolitis; sepsis; intrauterine or neonatal death., the perinatal outcome was reported.

He found thatthere was no statistically significant difference in the incidence of adverse perinatal outcome between the antegrade and retrograde isthmic blood flow groups. Further he concluded that Retrograde diastolic blood flow in the aortic isthmus presents a low sensitivity and low predictive value in predicting the adverse perinatal outcome in pregnancies complicated with IUGR.

\section{CONCLUSION}

The occurrence of retrograde blood flow in the AoI is associated with adverse perinatal outcome. Growth-restricted preterm foetuses showed decreased absolute velocities in the AoI, very likely reflecting reduced systemic blood flow. Combination of AoI \& umbilical artery Doppler is the best indicator for prediction of IUGR. Aortic Isthmus changes occur 24-48 hrs before deterioration of flow in Ductus Venosus. Consequently, Doppler study may be used for the prediction of fetal outcome to reduce the maternal and perinatal morbidity and mortality.

\section{REFERENCES}

1. Cruz-Martinez R, Figueras F, Hernandez-Andrade E, Oros D, Gratacos E. Changes in myocardial performance index and aortic isthmus and ductus venosus Doppler in term, small-for-gestational age fetuses with normal umbilical artery pulsatility index. Ultrasound Obstet Gynecol 2011; 38(4):400-5.

2. Eixarch F, Meler E, Iraola A, Illa M, Crispi F, Hernandez- Andrade E, Gratacos E, Figueras F. Neurodevelopmental outcome in 2-year-old infants who were small for gestational age term fetuses with cerebral blood flow redistribution. Ultrasound Obstet Gynecol 2008; 32(1): 894-899.

3. Baschat A, Gembrach U, Harman C. The sequence of changes in Doppler and biophysical parameters as severe fetal growth restriction worsens. Ultrasound Obstet Gynecol 2001; 18(5): 571-577.

4. Hecher K, Bilardo CM, Stigter RH, Villes Y, Hackeleor $\mathrm{BJ}$, Senat MV, et al.Monitoring of fetuses with intrauterine growth restriction: a longitudinal study. Ultrasound Obstet Gynecol 2001; 18(3): 564-570.

5. Ferrazi E, Bozzo M, Rigano S, Belotti M, Morabito A, Pardi G, Battaglia F, Galan H. Temporal sequence of abnormal Doppler changes in the peripheral and central circulatory systems of the severely growth-restricted fetus. Ultrasound Obstet Gynecol 2002; 19(2): 140-146.

6. Sonesson SE, Fouron JC. Doppler velocimetry of the aortic isthmus in human fetuses with abnormal velocity waveforms in the umbilical artery. Ultrasound Obstet Gynecol 1997;10(2):107-11.

7. Fouron JC, Gosselin J, Amiel-Tison C, [et al.]. Correlation between prenatal velocity waveforms in the aortic isthmus and neurodevelopmental outcome between the ages of 2 and 4 years. Am J Obstet Gynecol. 2001;184(1): 630-636.

8. Ropacka-Lesiak M, Korbelak T, Bręborowicz GH. Ocena przepływu krwi w tętnicy środkowej mózgu w ciąży niepowikłanej. Ginekol Pol. 2011;82 (3):185-190.

Source of Support: Nil; Conflict of Interest: None

Submitted: 01-12-2018; Accepted: 24-12-2018; Published online: 20-03-2019 